STRUCTURAL BIOLOGY

ISSN 2059-7983

Received 13 September 2021

Accepted 22 December 2021

Edited by M. Czjzek, Station Biologique de Roscoff, France

Keywords: glycosyl hydrolase family 5 ; endo-1,4- $\beta$-glucanases; transglycosylation; RBcel1.

PDB references: RBcel1, E135Q mutant, 7p6g; E135Q mutant in complex with cellotriose, 7p6h; Y201F mutant, 7p6i; Y201F mutant, glycosyl-enzyme intermediate, $7 \mathrm{p} 6 \mathrm{j}$

Supporting information: this article has supporting information at journals.iucr.org/d

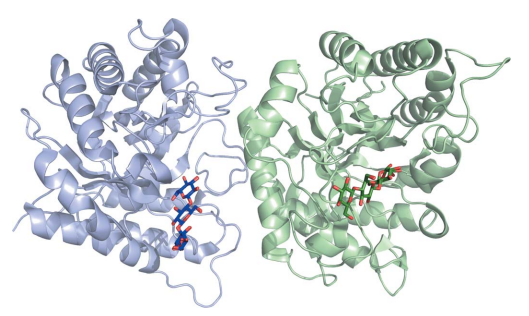
OPEN $\odot$ ACCESS

\section{Highlighting the factors governing transglycosylation in the GH5_5 endo-1,4- $\beta$-glucanase RBcel1}

\author{
Laetitia Collet, ${ }^{\text {a,b }}$ Corinne Vander Wauven, ${ }^{a}$ Yamina Oudjama, ${ }^{a}$ Moreno Galleni ${ }^{b}$ \\ and Raphaël Dutoit ${ }^{\mathrm{a} *}$
}

${ }^{\mathbf{a} L A B I R I S,} 1$ Avenue Emile Gryzon, 1070 Brussels, Belgium, and ${ }^{\mathbf{b}}$ Center for Protein Engineering (CIP), Biological Macromolecules, University of Liège, 13 Allée du 6 Août, 4000 Liège, Belgium. *Correspondence e-mail: rdutoit@spfb.brussels

Transglycosylating glycoside hydrolases (GHs) offer great potential for the enzymatic synthesis of oligosaccharides. Although knowledge is progressing, there is no unique strategy to improve the transglycosylation yield. Obtaining efficient enzymatic tools for glycan synthesis with GHs remains dependent on an improved understanding of the molecular factors governing the balance between hydrolysis and transglycosylation. This enzymatic and structural study of RBcel1, a transglycosylase from the GH5_5 subfamily isolated from an uncultured bacterium, aims to unravel such factors. The size of the acceptor and donor sugars was found to be critical since transglycosylation is efficient with oligosaccharides at least the size of cellotetraose as the donor and cellotriose as the acceptor. The reaction $\mathrm{pH}$ is important in driving the balance between hydrolysis and transglycosylation: hydrolysis is favored at $\mathrm{pH}$ values below 8 , while transglycosylation becomes the major reaction at basic $\mathrm{pH}$. Solving the structures of two RBcel1 variants, RBcel1_E135Q and RBcel1_Y201F, in complex with ligands has brought to light some of the molecular factors behind transglycosylation. The structure of RBcel1_E135Q in complex with cellotriose allowed a +3 subsite to be defined, in accordance with the requirement for cellotriose as a transglycosylation acceptor. The structure of RBcel1_Y201F has been obtained with several transglycosylation intermediates, providing crystallographic evidence of transglycosylation. The catalytic cleft is filled with (i) donors ranging from cellotriose to cellohexaose in the negative subsites and (ii) cellobiose and cellotriose in the positive subsites. Such a structure is particularly relevant since it is the first structure of a GH5 enzyme in complex with transglycosylation products that has been obtained with neither of the catalytic glutamate residues modified.

\section{Introduction}

Awareness of the role of glycans in biological processes has stimulated research and has led to a significant expansion in knowledge over the last two decades (Varki, 2017). Oligosaccharides and glycoconjugates are currently important therapeutic targets for many diseases. Their pure homogeneous forms are also increasingly used in glycobiology research and vaccine development (Boltje et al., 2009). Their production, however, remains challenging (Geyer \& Geyer, 2006; Boltje et al., 2009; Kiessling \& Splain, 2010; Wong \& Krasnova, 2019). The use of enzymes for in vitro synthesis of oligosaccharides has been seen as a promising alternative to chemical synthesis in recent decades, mainly due to their high stereoselectivity and regioselectivity, and their action in mild aqueous conditions ( $\mathrm{Li} \&$ Wang, 2016; Benkoulouche et al., 2019). Among them, transglycosylating glycoside hydrolases (GHs), known as transglycosylases, offer great potential for 
the synthesis of oligosaccharides as they do not require activated sugars as donors (Monsan et al., 2010; Bissaro et al., 2015; Danby \& Withers, 2016).

Only a few characterized GHs from several families in the CAZy database have been described as transglycosylases. The overall mechanism of transglycosylation is well known and generally follows the same reaction pattern as the retaining mechanism of hydrolytic GHs (Crout \& Vic, 1998; Bissaro et al., 2015). Indeed, the capacity to transglycosylate is a direct consequence of the double-displacement mechanism. After the glycosylation step, the donor sugar is covalently bound to the enzyme within its negatively numbered subsites. Transglycosylation occurs when a sugar hydroxyl group is used as an acceptor instead of a water molecule during the deglycosylation step. The reaction yields, however, remain low due to simultaneous hydrolysis of the products (Abdul Manas et al., 2018). It has been proposed that the ratio of hydrolysis to transglycosylation in transglycosylating $\mathrm{GHs}$ can be modulated by subtle molecular adjustments, such as modification of the donor/acceptor-binding sites and the orientation of the catalytic residues and the exclusion of water molecules from the catalytic site (Bissaro et al., 2015; Abdul Manas et al., 2018).

The occurrence of aromatic residues in the positive subsites of transglycosylating GHs is known to confer a high affinity for an acceptor sugar (Abdul Manas et al., 2018). Notably, a Pheclamp formed by two phenylalanine residues promotes interactions between the positive subsites and the acceptor sugar in the GH5_9 exo-1,3- $\beta$-glucanase from Candida albicans (Patrick et al., 2010). Another adaptation in the positive subsites is an increased affinity for a sugar acceptor via a positive charge provided by an arginine residue, as in the +2 subsite of several fungal GH5_7 $\beta$-mannanases (Dilokpimol et al., 2011; Rosengren et al., 2012). An equivalent arginine residue has also been observed in the +2 subsites of two transglycosylating GH5_5 cellulases: RBcel1 and Ps_Cel5A (Delsaute et al., 2013; Dutoit et al., 2019). However, this adaptation has not been observed in other structurally characterized GH5_5 enzymes (Dutoit et al., 2019). Therefore, the characterization of new transglycosylases is needed to identify the particularities and subtle differences in their catalytic clefts and to shed light on their genuine function.

RBcel1, an endoglucanase of the GH5_5 subfamily isolated from an uncultured bacterium, has aroused interest because of its ability to polymerize cellooligosaccharides in vitro under near-physiological conditions (Berlemont et al., 2009). In a recent study, we reported that a single substitution in its active site, Tyr201Phe, stabilizes the formation of the glycosylenzyme covalent intermediate (GEI; Collet et al., 2021). The structure of the GEI obtained with the natural oligosaccharide cellotriose delivered a series of snapshots of the reaction mechanism. Tyr201 is a highly conserved residue among GH5 family members and is believed to play an important role in both glycosylation and deglycosylation (Ducros et al., 1995; Sakon et al., 1996; Collet et al., 2021; Gonçalves et al., 2012; Kim \& Ishikawa, 2011; Zheng et al., 2012). The Tyr201Phe variant of RBcel1 retains transglycosylation activity, although it is reduced. Obtaining its structure with transglycosylation products could help to identify the structural motifs and residues involved in cellooligosaccharide synthesis.

Here, we report the influence of various factors on the transglycosylation activity of RBcel1. Firstly, the size of the acceptor sugar was found to be decisive and must be of at least three sugar units. This implies the existence of a third positive subsite which had not previously been described (Delsaute et al., 2013; Collet et al., 2021). The structure of the Glu135Gln variant of RBcel1 was solved in complex with cellotriose. It allowed the identification of the residues defining the +3 subsite. Secondly, in RBcel1 the reaction $\mathrm{pH}$ had a strong effect on hydrolysis and on the accumulation of transglycosylation products. Notably, at a $\mathrm{pH}$ above 8 hydrolysis is reduced and transglycosylation products tend to accumulate. Thirdly, the structure of the Tyr201Phe variant of RBcel1 was obtained in complex with transglycosylation products, highlighting several new key features of transglycosylation.

\section{Materials and methods}

\subsection{Cloning and mutagenesis of RBcel1}

The original pET-22b-RBcel1 expression vector used for the production of wild-type RBcel1 protein (RBcel1_WT) has been described previously (Berlemont et al., 2009), as well as the pBAD-RBcel1 vector for the production of the RBcel1 variant with Tyr201 substituted with a phenylalanine residue (RBcel1_Y201F; Collet et al., 2021). The RBcel1 variant with Glu135 substituted with a glutamine residue (RBcel1_E135Q) was produced from pET-22b-RBcel1 after targeted mutagenesis with the QuikChange Site-Directed Mutagenesis Kit (Agilent). All genetic constructs were verified by sequencing (Genetic Service Facility, University of Antwerp). Escherichia coli strain MC1061 was used for cloning and E. coli strain BL21 (DE3) was used for heterologous expression.

\subsection{Production and purification of RBcel1}

All constructs contain the original RBcel1 signal sequence which allows export of the recombinant protein into the periplasm. Consequently, all RBcel1 variant proteins were purified from periplasmic extracts. Cells producing RBcel1_WT and RBcel1_E135Q were grown and induced as described previously (Berlemont et al., 2009). RBcel1_Y201F was produced as described previously (Collet et al., 2021). Briefly, periplasmic extracts prepared as described in Garsoux et al. (2004) were loaded onto an ion-exchange column (SOURCE 15Q, $12 \mathrm{ml}$, GE Healthcare) equilibrated in $20 \mathrm{~m} M$ Tris- $\mathrm{HCl}$ $\mathrm{pH}$ 8.5. Proteins were eluted using a linear $\mathrm{NaCl}$ gradient from 0 to $500 \mathrm{mM}$. The fractions containing RBcel1 were pooled, concentrated and loaded onto a size-exclusion chromatography column (Superdex 75, $120 \mathrm{ml}$, GE Healthcare) equilibrated with $20 \mathrm{mM}$ sodium phosphate buffer $\mathrm{pH}$ 6.5. The relevant fractions were pooled and concentrated using an Amicon ultrafiltration unit (Merck Millipore) with a $10 \mathrm{kDa}$ cutoff. The purity was checked by SDS-PAGE. Protein concentrations were calculated using theoretical extinction 
Table 1

Macromolecule-production information.

\begin{tabular}{|c|c|c|}
\hline & RBcel1_E135Q & RBcel1_Y201F \\
\hline Source organism & Uncultured bacterium & Uncultured bacterium \\
\hline Expression vector & $\mathrm{pET}-22 \mathrm{~b}$ & pBAD-TOPO \\
\hline Expression host & Escherichia coli BL21(DE3) & Escherichia coli $\mathrm{MC} 1061$ \\
\hline \multirow{8}{*}{$\begin{array}{l}\text { Complete amino-acid sequence } \\
\text { of the construct produced }\end{array}$} & SVDLIGINVAGAEFTGGKLPGKHGTHYFFPPEGYFEYWSEQGI & SVDLIGINVAGAEFTGGKLPGKHGTHYFFPPEGYFEYWSEQGI \\
\hline & HTVRFPLKWERLQPSLNAELDDVYASLVDDMLDQAKENDIK & HTVRFPLKWERLQPSLNAELDDVYASLVDDMLDQAKENDIK \\
\hline & VILDVHNYARYRKKVIGTEDVPVSAYQDLMERIAKRWQGHD & VILDVHNYARYRKKVIGTEDVPVSAYQDLMERIAKRWQGHD \\
\hline & ALFAYDIMNQPYGSADKLWPAAAQAGIDGVRKYDKKRPLLI & ALFAYDIMNEPYGSADKLWPAAAQAGIDGVRKYDKKRPLLI \\
\hline & EGASWSSAARWPRYADELLKLKDPADNMVFSAHVYIDEDAS & EGASWSSAARWPRYADELLKLKDPADNMVFSAHVFIDEDAS \\
\hline & GSYKKGPGKDFEPMIGVKRVEPFVNWLKEHGKKGHIGEGIP & GSYKKGPGKDFEPMIGVKRVEPFVNWLKEHGKKGHIGEGIP \\
\hline & NDDERWLDAMDKLLAYLNENCIPINYWAAGPSWGNYKLSEP & NDDERWLDAMDKLLAYLNENCIPINYWAAGPSWGNYKLSIE \\
\hline & KDGEKRPQVALLKKYAAKDNCSDFGPAKAE & PKDGEKPQVALLKKYAAKDNCSDFGPAKAE \\
\hline
\end{tabular}

coefficients $\left(\Delta \varepsilon_{280}=80455 M^{-1} \mathrm{~cm}^{-1}\right.$ for RBcel1_WT and RBcel1_E135Q and $78965 \mathrm{M}^{-1} \mathrm{~cm}^{-1}$ for RBcel1_Y201F).

\subsection{Enzyme-activity assays}

2.3.1. Determination of kinetic parameters. The hydrolytic activity was assayed using 4-nitrophenyl $\beta$-glucoside (PNP $\beta$-G1), 2-chloro-4-nitrophenyl $\beta$-cellobioside (CIPNP $\beta$-G2), 2-chloro-4-nitrophenyl $\beta$-cellotrioside (CIPNP $\beta$-G3), 2-chloro-4-nitrophenyl $\beta$-cellotetraoside (ClPNP $\beta$-G4) and 2-chloro-4-nitrophenyl $\beta$-cellopentaoside (CIPNP $\beta$-G5) as substrates. CIPNP derivatives and PNP $\beta$-G1 were purchased from Megazyme and Sigma, respectively. The release of 4-nitrophenol (PNP) and 2-chloro-4-nitrophenol (ClPNP) was monitored by measuring the absorbance at $400 \mathrm{~nm}$ over $2 \mathrm{~min}$. The amount of CIPNP released is directly proportional to the rate of substrate hydrolysis. Kinetic parameters were determined under the initial rate conditions by nonlinear regression of the Michaelis-Menten equation. $0.2 \mu M$ enzyme was incubated with substrate in the range $0.3-6 \mathrm{~m} M$. The reaction was conducted at $37^{\circ} \mathrm{C}$ in $20 \mathrm{mM}$ sodium phosphate buffer $\mathrm{pH}$ 6.5. The kinetic parameters of RBcel1_E135Q and RBcel1_Y201F were determined using CIPNP $\beta$-G1 as a substrate in the range $0.125-6 \mathrm{~m} M$. The enzyme concentration was adapted due to the impaired activity of the variants: $36 \mu M$ for RBcel1_E135Q and $22 \mu M$ for RBcel1_Y201F.

2.3.2. Thin-layer chromatography. Thin-layer chromatography (TLC) was used to visualize the reaction products resulting from the activity of RBcel1 on different ClPNP $\beta$-cellooligosaccharides. Unless stated otherwise, the reaction mixtures consisted of $2 \mathrm{mM}$ CIPNP $\beta$-cellooligosaccharide in $20 \mathrm{~m} M$ sodium phosphate buffer $\mathrm{pH}$ 6.5. $10 \mu M$ enzyme was added to the reaction mixture at $4^{\circ} \mathrm{C}$ and then incubated for $5 \mathrm{~min}$ at $25^{\circ} \mathrm{C}$. The effect of $\mathrm{pH}$ on activity was determined by incubating $10 \mu M$ enzyme with $2 \mathrm{~m} M$ CIPNP $\beta$-G3 for $5 \mathrm{~min}$ at $25^{\circ} \mathrm{C}$ in $20 \mathrm{~m} M$ citrate-phosphate-CHES buffer with the $\mathrm{pH}$ adjusted in the range $\mathrm{pH} 4$ to $\mathrm{pH} 9$ (Berlemont et al., 2009). Size-reference ladders were prepared by mixing PNP $\beta$-G1, CIPNP $\beta$-G2, CIPNP $\beta$-G3, glucose (G1), cellobiose (G2), cellotriose (G3), cellotetraose (G4), cellopentaose (G5) and cellohexaose (G6) at a final concentration of $1 \mathrm{~m} M$ each. G2 to G6 cellooligosaccharides were purchased from Megazyme. The reaction was stopped by heating the samples at $95^{\circ} \mathrm{C}$ for
$5 \mathrm{~min}$. After centrifugation at $10000 \mathrm{~g}$ for $2 \mathrm{~min}, 40 \mu \mathrm{l}$ of the reaction mixture was evaporated to $\sim 8 \mu \mathrm{l}$, which was spotted onto silica gel 60 TLC glass plates (Merck Millipore). Chromatograms were developed in a mixture of butanol/acetic acid/water [50:25:25(v:v:v)]. Reaction products were revealed by spraying the plates with 1-naphthol $(2 \%)$ in ethanol/ concentrated sulfuric acid/water $[83 / 10 / 75(v: v: v)]$ and heating at $121^{\circ} \mathrm{C}$ for $10 \mathrm{~min}$.

2.3.3. PACE analysis. Polyacrylamide carbohydrate electrophoresis (PACE) was performed as described previously (Collet et al., 2021) with the following adaptations. To determine the potential acceptors used in transglycosylation, 4,6$O$-benzylidene-2-chloro-4-nitrophenyl- $\beta$-cellotrioside (ClPNP $\beta$-BG3; from the $\mathrm{K}$-CellG3 cellulase assay kit, Megazyme) was used as a donor. G1, G2, G3 and G4 were used as donor sugars. Unless stated otherwise, $1 \mathrm{~m} M$ CIPNP $\beta$-BG3 was mixed with $1 \mathrm{~m} M$ of the acceptor sugar in $20 \mathrm{~m} M$ sodium phosphate buffer $\mathrm{pH}$ 6.5. As ClPNP $\beta$-BG3 is supplied as a solution in DMSO, the reaction mixture contained $10 \%(v / v)$ DMSO. The reaction was started by adding $10 \mu M$ enzyme to the reaction mixture kept at $4{ }^{\circ} \mathrm{C}$ and was immediately incubated at $25^{\circ} \mathrm{C}$ for $10 \mathrm{~min}$. The reaction was stopped by adding $0.5 \%(v / v)$ formic acid. To separate 4,6-O-benzylidene$\beta$-cellotrioside (BG3) from $\mathrm{G} 4$, the gel was run with a constant current of $18 \mathrm{~mA}$ for $90 \mathrm{~min}$ instead of $60 \mathrm{~min}$. The hydrolysis and transglycosylation products of RBcel1_Y201F were also determined by PACE using G3 under conditions close to those of crystallogenesis. $166 \mu M$ RBcel1_Y201F was incubated with $10 \mathrm{mMG}$ at $20^{\circ} \mathrm{C}$ in $0.1 M$ Tris $\mathrm{pH}$ 7. Samples were taken at different incubation times ( 1 min to 20 days) and the reaction was stopped by adding $0.5 \%(v / v)$ formic acid prior to PACE.

\subsection{Crystallization}

RBcel1_E135Q and RBcel1_Y201F (Table 1) were crystallized using the hanging-drop vapor-diffusion method at 293 K. Crystallization was set up in EasyXtal plates (Qiagen). RBcel1_Y201F, stored at a concentration of $400 \mu M$ in $20 \mathrm{mM}$ sodium phosphate $\mathrm{pH} 6.5$, was mixed in a 1:1 ratio with a well buffer consisting of $0.1 M$ Tris, $17.5 \%$ PEG $600 \mathrm{pH}$ 7. For co-crystallization of RBcel1_Y201F with cellotriose (G3), the enzyme was incubated with $1 \mathrm{~m} M \mathrm{G} 3$ for $1 \mathrm{~h}$ at $4{ }^{\circ} \mathrm{C}$. Drops consisted of $2 \mu \mathrm{l}$ of the enzyme-G3 reaction mixture and $2 \mu \mathrm{l}$ 
Table 2

Crystallization.

Values in parentheses are for the outer shell.

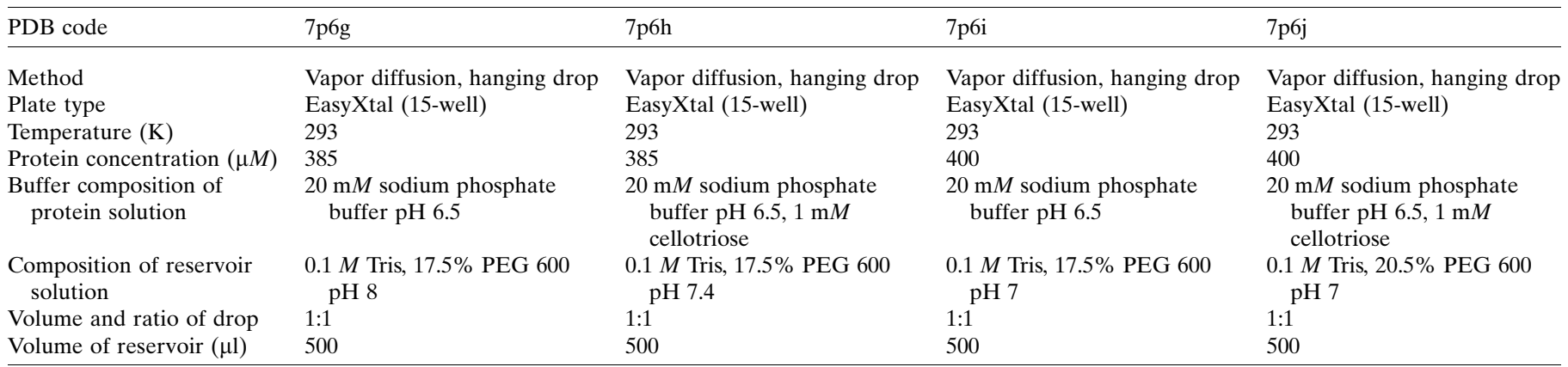

Table 3

Data collection and processing.

Values in parentheses are for the outer shell.

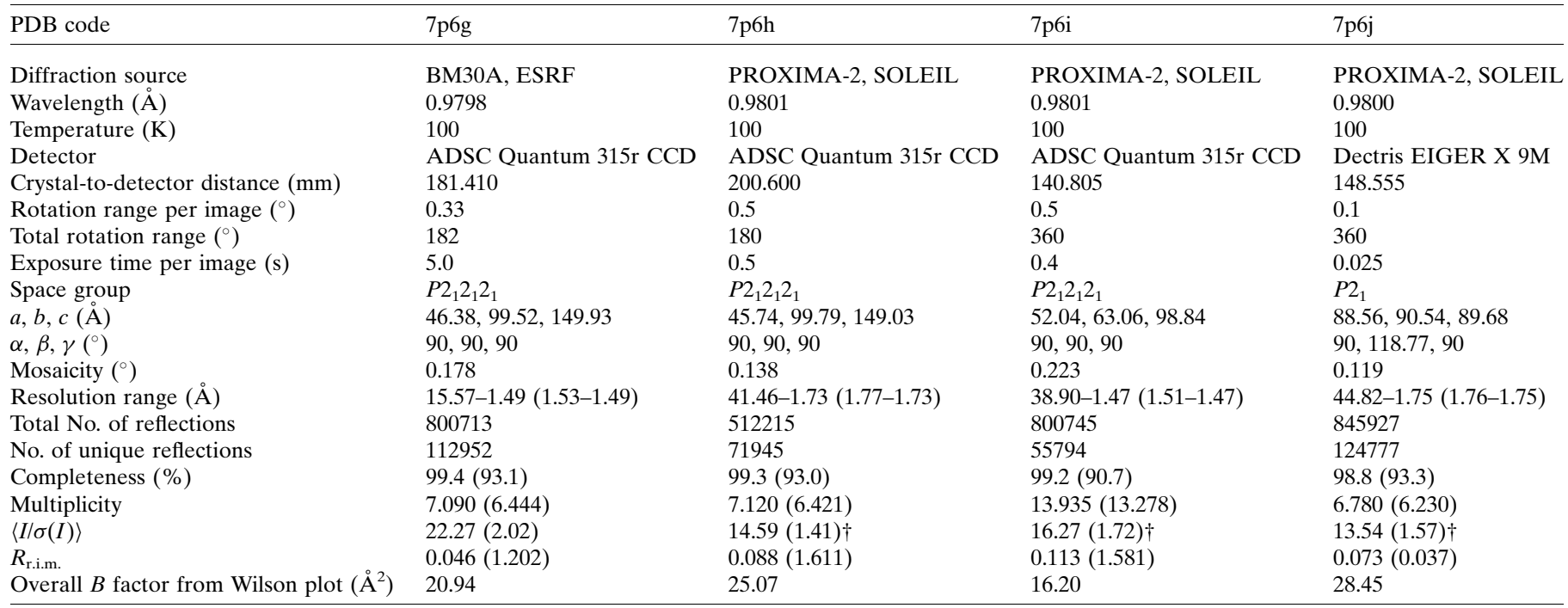


and $1.79 \AA$ for PDB entries 7p6h, 7p6i and 7p6j, respectively.

$0.1 M$ Tris, $20.5 \%$ PEG $600 \mathrm{pH}$ 7.0. Single crystals appeared after a few hours and grew to maximum dimensions within two days at $293 \mathrm{~K}$. Crystals were picked for cryogenization after one week. RBcel1_E135Q was crystallized by mixing $2 \mu \mathrm{l}$ $385 \mu M$ protein in $20 \mathrm{~m} M$ sodium phosphate buffer $\mathrm{pH} 6.5$ with $2 \mu \mathrm{l} 0.1 \mathrm{M}$ Tris-HCl, $17.5 \%$ PEG $600 \mathrm{pH}$ 7.4. To cocrystallize RBcel1_E135Q with G3, $1 \mathrm{~m} M$ G3 was added to a drop consisting of $2 \mu \mathrm{l} 385 \mu \mathrm{M}$ protein solution and $2 \mu \mathrm{l} 0.1 \mathrm{M}$ Tris- $\mathrm{HCl}, 17.5 \%$ PEG $600 \mathrm{pH}$ 7.4. Microseeding was necessary to improve the crystal shape and size. Before picking up the crystals, the drops were equilibrated for $2 \mathrm{~h}$ against a $500 \mu \mathrm{l}$ reservoir consisting of $0.1 M$ Tris, $30 \%$ PEG $600 \mathrm{pH} 7.4$ for cryoprotection. The crystallization conditions are summarized in Table 2.

\subsection{Data collection and processing}

Diffraction data for RBcel1_E135Q were collected on the FIP-BM30A beamline (Ferrer, 2001) at ESRF, Grenoble,
France and those for RBcel1_E135Q in complex with G3 and RBcel1_Y201F on the PROXIMA-2 beamline at SOLEIL, Saint-Aubin, France. Diffraction data were indexed using the $X D S$ program package (Kabsch, 2010). The statistics of data collection and indexing are summarized in Table 3 . The four structures were determined by molecular replacement with Phaser-MR in Phenix (McCoy et al., 2007; Liebschner et al., 2019) using the coordinates of RBcel1 (PDB entry 4ee9; Delsaute et al., 2013) as a search model. The models were built using phenix.autobuild (Liebschner et al., 2019) and Crystallographic Object-Oriented Toolkit (Coot; Emsley et al., 2010). Multiple rounds of refinement were performed using phenix.refine (Liebschner et al., 2019). The stereochemical quality of the models was assessed using MolProbity (Chen et al., 2010). The structure solutions and refinement statistics for the four structures are presented in Table 4. Protein-ligand interactions were analyzed using PDBeMotif (Golovin \& Henrick, 2008). Structures were illustrated using the PyMOL molecular-graphics system version 0.9 (Schrödinger). 
Table 4

Structure solution and refinement.

\begin{tabular}{|c|c|c|c|c|}
\hline PDB code & $7 \mathrm{p} 6 \mathrm{~g}$ & $7 \mathrm{p} 6 \mathrm{~h}$ & $7 \mathrm{p} 6 \mathrm{i}$ & $7 \mathrm{p} 6 \mathrm{j}$ \\
\hline Resolution range $(\AA)$ & $\begin{array}{l}15.57-1.49 \\
\quad(1.51-1.49)\end{array}$ & $\begin{array}{l}41.46-1.73 \\
\quad(1.75-1.73)\end{array}$ & $\begin{array}{l}38.90-1.47 \\
\quad(1.49-1.47)\end{array}$ & $\begin{array}{l}44.82-1.75 \\
\quad(1.76-1.75)\end{array}$ \\
\hline Completeness (\%) & 99.4 & 99.3 & 99.1 & 99.0 \\
\hline$\sigma$ Cutoff & $F>1.360 \sigma(F)$ & $F>1.360 \sigma(F)$ & $F>1.330 \sigma(F)$ & $F>1.370 \sigma(F)$ \\
\hline No. of reflections, working set & $107185(3013)$ & $68314(2300)$ & $51012(1388)$ & 118499 (3399) \\
\hline No. of reflections, test set & $5642(159)$ & 3595 (121) & $4764(92)$ & 6235 (179) \\
\hline Final $R_{\text {cryst }}$ & $0.174(0.2947)$ & $0.167(0.3701)$ & $0.178(0.4038)$ & $0.172(0.4221)$ \\
\hline Final $R_{\text {free }}$ & $0.193(0.3323)$ & $0.194(0.3757)$ & $0.193(0.4633)$ & $0.202(0.4802)$ \\
\hline Cruickshank DPI & 0.075 & 0.148 & 0.082 & 0.206 \\
\hline \multicolumn{5}{|l|}{ No. of non-H atoms } \\
\hline Protein & 5108 & 5146 & 2570 & 10202 \\
\hline Ligand & 20 & 84 & 24 & 302 \\
\hline Water & 877 & 607 & 483 & 1159 \\
\hline Total & 6005 & 5837 & 3077 & 11663 \\
\hline \multicolumn{5}{|l|}{ R.m.s. deviations } \\
\hline Bond lengths $(\AA)$ & 0.004 & 0.007 & 0.003 & 0.004 \\
\hline Angles $\left(^{\circ}\right)$ & 0.673 & 0.879 & 0.650 & 0.728 \\
\hline \multicolumn{5}{|l|}{ Average $B$ factors $\left(\AA^{2}\right)$} \\
\hline Protein & 26.98 & 30.10 & 19.33 & 36.86 \\
\hline Ligand & 36.66 & 31.69 & 22.66 & 38.83 \\
\hline Water & 38.65 & 40.84 & 34.09 & 41.91 \\
\hline \multicolumn{5}{|l|}{ Ramachandran plot } \\
\hline Most favored (\%) & 98.42 & 98.11 & 97.81 & 98.03 \\
\hline Allowed (\%) & 1.58 & 1.89 & 2.19 & 1.90 \\
\hline
\end{tabular}

The activity of RBcel1 was assayed on chromogenic cellooligosaccharides of increasing size and the kinetic parameters were determined. As shown in Table 5, no significant activity was observed on PNP $\beta$-G1 or CIPNP $\beta$-G2, in contrast to longer substrates, indicating that at least three negatively numbered subsites must be occupied for hydrolysis to occur. RBcel1 displayed the highest catalytic efficiency with CIPNP $\beta$-G4 as a substrate, which was nearly ten times that with CIPNP $\beta-\mathrm{G} 3$. Such a difference in catalytic efficiency is mainly due to the affinity for the substrate. Indeed, the $K_{\mathrm{m}}$ for CIPNP $\beta$-G4 was $0.3 \mu M$, compared with $2.4 \mu M$ for CIPNP $\beta$-G3, while both substrates were hydrolysed at a similar rate. Since the catalytic efficiency was not increased with CIPNP $\beta$-G5, only four negatively numbered subsites of RBcel1 need to be occupied, which is

Table 5

Apparent parameters for the hydrolysis of chromogenic cellooligosaccharides by RBcel1.

$0.2 \mu M$ enzyme was incubated with different substrates at concentrations ranging from 0.3 to $6 \mathrm{mM}$. The kinetic parameters were determined according to the release of CIPNP monitored by measuring the absorbance at $400 \mathrm{~nm}$. The reactions were performed in $20 \mathrm{mM}$ sodium phosphate $\mathrm{pH} 6.5$ at $37^{\circ} \mathrm{C}$. Standard error is given for each value with $n=3$.

\begin{tabular}{lllll}
\hline Substrate & $\begin{array}{l}\text { Cellooligosaccharide } \\
\text { equivalent }\end{array}$ & $k_{\text {cat }}\left(\mathrm{s}^{-1}\right)$ & $K_{\mathrm{m}}(\mathrm{m} M)$ & $\begin{array}{l}k_{\text {cat }} / K_{\mathrm{m}} \\
\left(\mathrm{m} M^{-1} \mathrm{~s}^{-1}\right)\end{array}$ \\
\hline PNP $\beta$-G1 & G2 & n.d. $\dagger$ & n.d. $\dagger$ & n.d. $\dagger$ \\
ClPNP $\beta$-G2 & G3 & n.d. $\dagger$ & n.d. $\dagger$ & n.d. $\dagger$ \\
ClPNP $\beta$-G3 & G4 & $0.52 \pm 0.02$ & $2.37 \pm 0.26$ & $0.22 \pm 0.02$ \\
ClPNP $\beta$-G4 & G5 & $0.58 \pm 0.01$ & $0.30 \pm 0.03$ & $1.88 \pm 0.19$ \\
ClPNP $\beta$-G5 & G6 & $0.049 \pm 0.01$ & $0.34 \pm 0.05$ & $1.45 \pm 0.14$ \\
\hline
\end{tabular}

$\dagger$ No significant activity was detected.

\section{Results and discussion}

\subsection{Importance of the size of the donor sugars}

Previously, the catalytic cleft of RBcel1 has been described as consisting of four negatively and two positively numbered subsites. The six subsites were identified by (i) comparing the structure of RBcel1 with those of structural homologs belonging to the GH5 family (Delsaute et al., 2013) and (ii) obtaining the structure of the Glu135Ala mutant in complex with G3 (Collet et al., 2021). However, it remained unclear whether the subsites had to be completely occupied for hydrolysis or transglycosylation to occur. During the first step of the reaction, the part of the substrate located in the negatively numbered subsites (following the nomenclature established by Davies et al., 1997) becomes covalently linked to the nucleophilic residue, while the part initially hosted in the positive subsites is released. Chromogenic cellooligosaccharides have been used to determine the effect of substrate size on the first displacement (Desmet et al., 2007). consistent with the structural analysis of the catalytic cleft.

The reaction products resulting from hydrolysis of the chromogenic cellooligosaccharides were analyzed by TLC. As expected, no activity was observed with PNP $\beta$-G1 and CIPNP $\beta$-G2 (Supplementary Fig. S1). On the other hand, RBcel1 effectively degraded CIPNP $\beta$-G3 and CIPNP $\beta$-G4 into various products, including transglycosylation products. For instance, RBcel1 generated the hydrolysis products G2 and G3 from CIPNP $\beta$-G3 and the transglycosylation products $\mathrm{G} 4$ and G5 (Supplementary Fig. S1). CIPNP $\beta$-G1 and ClPNP $\beta$-G2 were also formed during the degradation of CIPNP $\beta$-G3. Considering these results, the products are more likely to be produced by the hydrolysis of transglycosylation products rather than from an alternate hydrolysis of the substrate. Consequently, the kinetic parameters shown in Table 5 are probably underestimated since both hydrolysis and transglycosylation occur. For further characterization of the transglycosylase activity, CIPNP $\beta$-G3 was preferred over CIPNP $\beta$-G4, which contained several contaminants that hinder the interpretation of the data (Supplementary Fig. S1).

\subsection{Impact of the $\mathrm{pH}$ on transglycosylation}

In their review, Abdul Manas et al. (2018) discuss different factors that favor either hydrolysis or transglycosylation. Among them, pH can influence transglycosylation by modulating the protonation states of catalytically important residues. Consequently, the influence of the $\mathrm{pH}$ on the ability of RBcel1 to transglycosylate was investigated using CIPNP $\beta$-G3. RBcel1 was incubated with CIPNP $\beta$-G3 at different $\mathrm{pH}$ values and the reaction products were analyzed by TLC. As shown in Fig. 1, CIPNP $\beta$-G3 was almost completely consumed at $\mathrm{pH} 6.5$ to 7.5 , which correspond to the previously published optimum $\mathrm{pH}$ of the hydrolysis activity (Berlemont et al., 2009). 
G4 was observed at all $\mathrm{pH}$ values, indicating that transglycosylation occurred over a wide range of $\mathrm{pH}$ values. The transglycosylation products, however, varied significantly. At the optimum $\mathrm{pH}$ for hydrolysis, ranging from $\mathrm{pH} 6.5$ to 7.5 , their diversity was the lowest, probably due to rapid hydrolysis of the newly formed transglycosylation products. At these $\mathrm{pH}$ values the spot intensities of the hydrolysis products (i.e. $\mathrm{G} 2$, G3, CIPNP $\beta$-G2 and CIPNP $\beta$-G1) were accordingly the highest.

At $\mathrm{pH}$ values below 6.5 the degradation rate of CIPNP $\beta$-G3 was slower, enabling the detection of products formed at the very beginning of the reaction. For instance, G4 and CIPNP $\beta$-G2 are the only products observed at $\mathrm{pH} 4$ (see Fig. 1), and probably result from hydrolysis of the transglycosylation product ClPNP $\beta$-G6. Above $\mathrm{pH} 8$ the diversity of transglycosylation products was the highest, with a bountiful accumulation of G4, G5, G6 and even CIPNP $\beta$-G4. Such an accumulation could not be explained by a slower reaction rate since the initial substrate (CIPNP $\beta$-G3) was almost completely consumed.

To our knowledge, the influence of $\mathrm{pH}$ on transglycosylation remains ill-described due to a scarcity of data. For instance, Lundemo and coworkers reported that $\mathrm{pH}$ influences hydrolysis only, without any effect on transglycosylation, for a GH1 $\beta$-glucosidase from Thermotoga neapolitana (Lundemo et al., 2017). On the contrary, Oikawa and coworkers observed that the transglycosylation activity was increased at acidic $\mathrm{pH}$ for an endo- $\beta$-glucanase from Rhodotorula glutinis (Oikawa et al., 2001). A likely explanation for the accumulation of transglycosylation products at high $\mathrm{pH}$ values could reside in the protonation state of Glu135, the catalytic acid/base residue

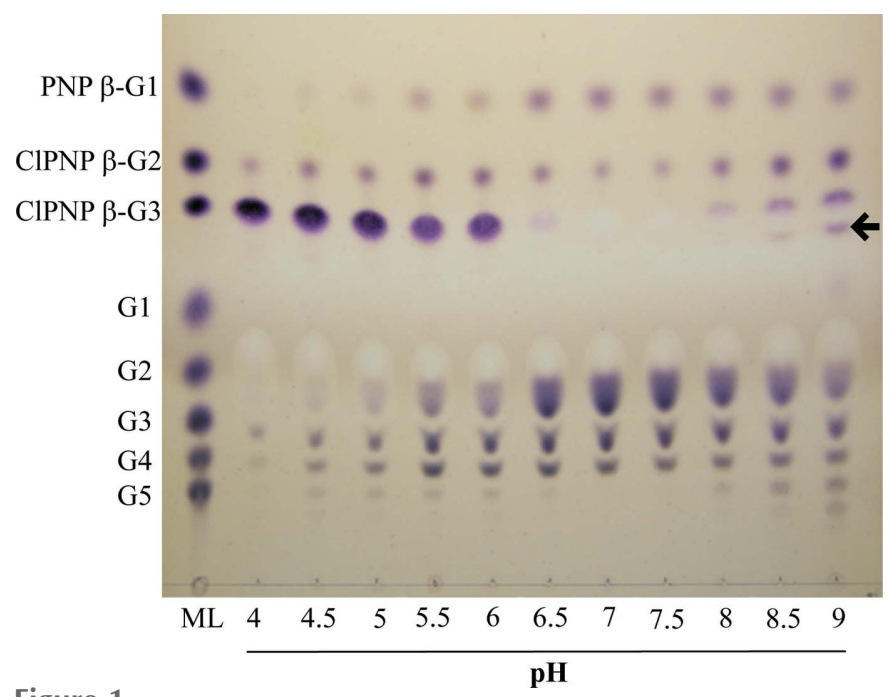

Figure 1

TLC analysis of the products of RBcel1_WT activity on CIPNP $\beta$-G3 over a range of $\mathrm{pH}$ values from 4 to $9.10 \mu M$ enzyme was incubated with $2 \mathrm{~m} M$ CIPNP $\beta$-G3 in $20 \mathrm{~m} M$ citrate-phosphate-CHES buffer for $5 \mathrm{~min}$ at $25^{\circ} \mathrm{C}$. The following cellooligosaccharides and CIPNP derivatives were used as standards (1 $\mathrm{m} M$ of each; lane ML): glucose (G1), cellobiose (G2), cellotriose (G3), cellotetraose (G4), cellopentaose (G5), 4-nitrophenyl $\beta$-glucoside (PNP $\beta$-G1), 2-chloro-4-nitrophenyl $\beta$-cellobioside (CIPNP $\beta$-G2) and 2-chloro-4-nitrophenyl $\beta$-cellotrioside (ClPNP $\beta$-G3). The presence of 2-chloro-4-nitrophenyl $\beta$-cellotetraoside is marked by an arrow.
$\left(\mathrm{Glu}_{\mathrm{A} / \mathrm{B}}\right)$ in $\mathrm{RBcel1}$. We propose that at basic $\mathrm{pH}$ values Glu135 is maintained in a deprotonated state. As previously described for the RBcel1_E135A variant (Collet et al., 2021), a lack of protonic assistance from Glu135 would totally prevent the hydrolysis of natural sugars but would still provide assistance as a base essential to transglycosylation. Consequently, higher $\mathrm{pH}$ values promote transglycosylation with CIPNP $\beta$-G3 and prevent hydrolysis of the newly formed products.

\subsection{Importance of the size of the acceptor sugar for the} transglycosylation activity

As mentioned earlier, RBcel1 can produce transglycosylation products with ClPNP $\beta$-G3. Transglycosylation occurs when an acceptor sugar occupies the positively numbered subsites. The acceptor sugar is activated by $\mathrm{Glu}_{\mathrm{A} / \mathrm{B}}$ and releases the GEI during the second step of the reaction. Although two positively numbered subsites have been described in the structure of RBcel1 (Delsaute et al., 2013;

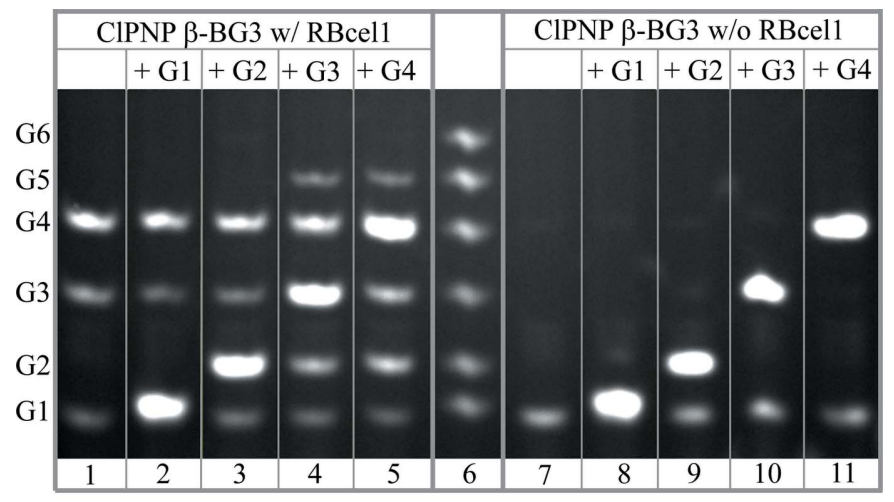

(a)

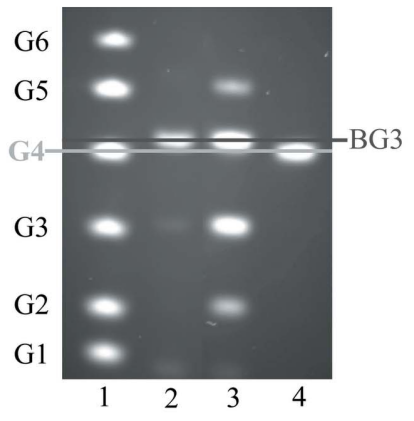

(b)

Figure 2

(a) PACE analysis of the activity of RBcel1_WT on 4,6- $O$-benzylidene-2chloro-4-nitrophenyl- $\beta$-cellotrioside (CIPNP $\beta$-BG3) with different sugar acceptors. Lanes $1-5$ show the reaction products when $1 \mathrm{~m} M$ CIPNP $\beta$-BG3 was incubated with $10 \mu M$ enzyme for $10 \mathrm{~min}$ at $25^{\circ} \mathrm{C}$ : lane 1 , without an acceptor; lane 2, with $1 \mathrm{mM} \mathrm{G1}$; lane 3, with $1 \mathrm{~m} M$ G2; lane 4, with $1 \mathrm{~m} M \mathrm{G} 3$; lane 5, with $1 \mathrm{~m} M \mathrm{G} 4$. Lanes 7-11 show the corresponding control reaction mixtures incubated without enzyme: lane 7, CIPNP $\beta$-BG3; lane 8, ClPNP $\beta$-BG3 + G1; lane 9, ClPNP $\beta$-BG3 + G2; lane 10, CIPNP $\beta$-BG3 + G3; lane 11, CIPNP $\beta$-BG3 + G4. Lane 6: oligosaccharide size ladder comprising $\mathrm{G} 1, \mathrm{G} 2, \mathrm{G} 3, \mathrm{G} 4, \mathrm{G} 5$ and G6. (b) PACE analysis to validate 4,6- $O$-benzylidene- $\beta$-cellotrioside (BG3) as a product of the hydrolysis of CIPNP $\beta$-BG3. Lane 1, oligosaccharide size ladder comprising G1, G2, G3, G4, G5 and G6; lane 2, $1 \mathrm{mM}$ BG3 incubated without enzyme; lane 3 , products of the incubation of $1 \mathrm{~m} M$ CIPNP $\beta$-BG3 with $1 \mathrm{~m} M$ G3 and $10 \mu M$ enzyme; lane $4,1 \mathrm{~m} M$ G4 incubated without enzyme. 
Collet $e$ al., 2021), it was still unknown whether the size of the acceptor sugar influences transglycosylation. This aspect was investigated here using CIPNP $\beta$-BG3 as a donor and various cellooligosaccharides, from G1 to G4, as acceptors. ClPNP $\beta$-BG3 is a chromogenic G3 with its nonreducing end protected by a benzylidene group. Therefore, it cannot be used as an acceptor. As TLC could not be performed with benzylidene-linked oligosaccharides, PACE was used to analyze the reaction products. Inherently to this method, however, the chromogenic derivatives cannot be observed due to the absence of a reducing end.

As shown in Fig. 2(a), in the absence of a cellooligosaccharide acceptor the hydrolysis of CIPNP $\beta$-BG3 produced two products with the apparent sizes of G4 and G3. Since the nonreducing end of the substrate is blocked, the former should therefore correspond to 4,6- $O$-benzylidene- $\beta$-D-cellotriose (BG3) and not to G4, and the latter to BG2 and not to G3. Indeed, when PACE was performed with a longer migration time, BG3 clearly separated from G4 (Fig. $2 b$ ). Unequivocally, the hydrolysis of CIPNP $\beta$-BG3 generated BG3, and the use of this substrate as a donor was validated. In the presence of G1 as an acceptor only the BG3 hydrolysis products were observed, meaning that no transglycosylation had occurred (Fig. 2a). With G2 as an acceptor, a faint band corresponding to G6 was observed, indicating that transglycosylation had occurred (Fig. 2a). With G3 and G4 as acceptors, a transglycosylation product corresponding to G5 accumulated in the reaction mixture along with G2 (Fig. 2a). Our results suggest that transglycosylation is dependent on the length of the acceptor sugar and needs an acceptor of at least three glucose units to proceed efficiently.

\subsection{Positioning of $G 3$ as the acceptor sugar: structure of} RBcel1_E135Q with G3

G3 being a better acceptor than G2 is an indication of the existence of a third positively numbered subsite in the catalytic cleft of RBcel1. This additional subsite, however, had not been observed in the previous characterization of the RBcel1 structure. In the structure of RBcel1_E135A in complex with G3 (Collet et al., 2021), a G3 molecule was found spanning the -1 to +2 subsites, and no G3 was found solely occupying positively numbered subsites. In this variant, the position of G3 could have resulted from the lack of steric constraints. Thus, to mimic the presence of the $\mathrm{Glu}_{\mathrm{A} / \mathrm{B}}$ residue, the variant RBcel1_E135Q was generated to determine its structure with G3. The activity of this variant was dramatically impaired with ClPNP $\beta$-G3 as substrate, with a $k_{\text {cat }}$ of $0.219 \pm 0.009 \times$ $10^{-3} \mathrm{~min}^{-1}$ and a $K_{\mathrm{m}}$ of $0.263 \pm 0.041 \mathrm{mM}$. The kinetic parameters strongly indicate that both the glycosylation and deglycosylation steps are affected by the substitution of Glu135 with a glutamine residue. RBcel1_E135Q was then co-crystallized with G3 and a data set was obtained, and the structure of the complex was solved at $1.73 \AA$ resolution.

The asymmetric unit contains two monomers, each in complex with a differently positioned G3 molecule (Fig. 3a). In monomer $B$ the $\mathrm{G} 3$ molecule occupies the -4 to -2 subsites (Supplementary Fig. S2), but in monomer $A$ it occupies the positively numbered subsites only, lying beyond the +2 subsite (Fig. $3 b$ ). Its third glucose unit is placed in a poorly defined +3 subsite, making a few interactions with the carbonyl of Asp205 and a water molecule coordinated by the carbonyl of Glu204 and the side chain of Arg226 (Fig. 3b). The catalytic residues are placed differently depending on where the ligand is positioned. The side chain of the nucleophile Glu245 is positioned as described for RBcel1_WT in monomer $A$ and the apo form of RBcel1_E135Q. In monomer $B$ it adopts several conformations: its carboxylate is rotated by $50^{\circ}$ along the $\mathrm{C}^{\beta}$ axis, leading to a rotamer change from $\mathbf{m t}-10^{\circ}$ to $\mathbf{t t} 0^{\circ}$ (Fig. 3c). The same rotation of Glu245 was previously described during the formation of the GEI (Collet et al., 2021). It seems that occupancy of the farther negative subsites is required for Glu245 to be correctly positioned to form the GEI. The $\mathbf{m t}-10^{\circ}$ to $\mathbf{t t} 0^{\circ}$ rotation seems to impact the position of the side chain of Tyr201. When Glu245 adopts the $\mathbf{t t} 0^{\circ}$ conformation, as seen in monomer $B$ (Fig. 3c), the hydroxyl group of Tyr201 is displaced by $1 \AA$ compared with monomer $A$ and the apo form of RBcel1_E135Q. The aromatic plane of

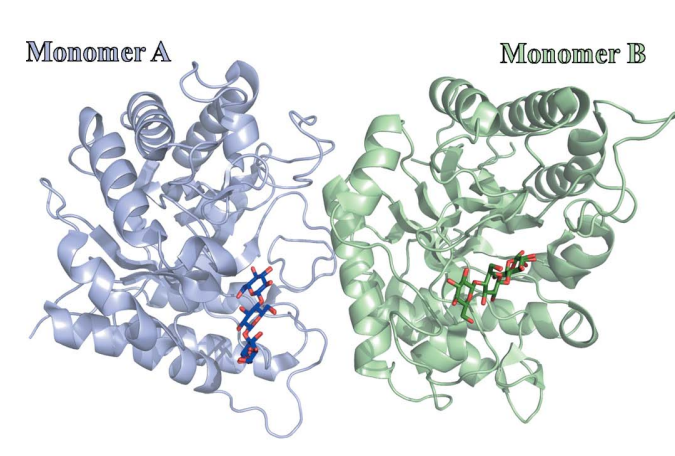

(a)

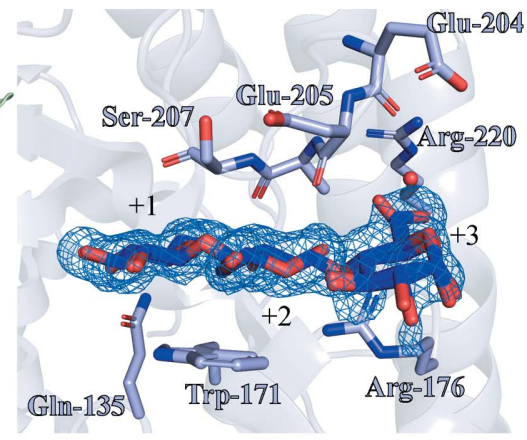

(b)

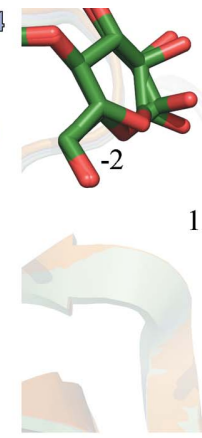

Glu-24

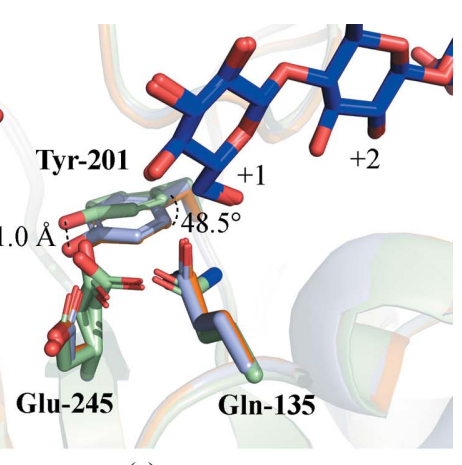

(c)

Figure 3

(a) Overall structure of RBcel1_E135Q in complex with G3 (PDB entry 7p6h). Monomer $A$ and monomer $B$ are represented in light blue and light green, respectively, while their bound G3 molecules are colored dark blue and dark green, respectively. $(b)$ Close-up view of the +1 to +3 subsites consisting of Trp171, Arg176, Glu204, Glu205, Ala206 and Ser207. The water molecule interacting with the glucose unit in the +3 subsite is represented as a red sphere. The $2 F_{\mathrm{o}}-F_{\mathrm{c}}$ map around G3 is shown as a blue mesh. (c) Structural alignment of RBcel1_E135Q in complex with G3 (in blue and green for monomer $A$ and monomer $B$, respectively) with the apo form of RBcel1_E135Q (PDB entry 7p6g, orange). The positions of three residues of the -1 subsite are shown: Gln135 (Glu $\mathrm{A}_{\mathrm{B}}$ substituted by a glutamine residue), Tyr201 and Glu245 (the catalytic nucleophile). 
Tyr201 is also tilted by $48.5^{\circ}$ in monomer $B$. Furthermore, OE1 of $\mathrm{G} \ln 135$ is rotated by $50^{\circ}$ in monomer $B$ compared with the position of OE1 of Gln135 in monomer $A$ and the apo form of RBcel1_E135Q (Fig. 3c). To our knowledge, such a displacement of the acid/base residue has not been reported for other GH5 enzymes.

\subsection{Snapshots of RBcel1_Y201F on the way to transglycosylation}

Our previous study of RBcel1 showed that the substitution of Tyr201 with a phenylalanine residue drastically slows the deglycosylation step, resulting in accumulation of the GEI



Figure 4

Time

PACE analysis of RBcel1_Y201F activity on G3 after different incubation times. $166 \mu M$ RBcel1_Y201F was incubated with $10 \mathrm{mM}$ G3 at $20^{\circ} \mathrm{C}$ in $0.1 M$ Tris buffer $\mathrm{pH} 7.7 \mathrm{~d} * 3$ corresponds to the reaction incubated for seven days loaded three times.
(Collet et al., 2021). The GEI, however, was released over time and the transglycosylase activity of RBcel1_Y201F was maintained. Therefore, it should be possible to obtain snapshots of the transglycosylation from the structure of this variant in complex with cellooligosaccharides. The kinetic parameters of RBcel1_Y201F were determined using ClPNP $\beta$-G3. The $k_{\text {cat }}$ and $K_{\mathrm{m}}$ were $0.194 \pm 0.023 \times 10^{-3} \mathrm{~min}^{-1}$ and $0.077 \pm 0.010 \mathrm{~m} M$, respectively, confirming that Tyr201 is important in catalysis. The activity of RBcel1_Y201F was also measured with G3 at an enzyme:substrate ratio close to the crystallogenesis conditions. As shown in Fig. 4, after seven days of incubation transglycosylation products were observed such as G4 (the main transglycosylation product), G5 and G6. Consequently, RBcel1_Y201F was co-crystallized with G3 for one week prior to cryogenization and data collection. Its structure was solved at $1.74 \AA$ resolution along with the structure of the apo form for comparison.

The structure of the apo form of RBcel1_Y201F contains one monomer per asymmetric unit. A Tris molecule resides in the -1 subsite, as in the structure of RBcel1_WT. The structure of RBcel1_Y201F co-crystallized with G3 contains four monomers per asymmetric unit, with each monomer containing ligands ranging from G2 to G6 in the catalytic cleft (Fig. 5a). The presence of cellooligosaccharides longer than G3 within the negatively numbered subsites provides crystallographic evidence for transglycosylation. The whole catalytic cleft is summarized in Fig. 5(b), emphasizing the residues interacting with the ligands. The real-space correlation coefficients of each ligand are presented in Supplementary Table S1. In monomer $A$, a G4 molecule covalently bound to Glu245 occupies the -4 to -1 subsites (Fig. $6 a$ ). In monomer $D$, G3 and G4 were placed in the negative subsites according to realspace correlation coefficients and median $B$ factors (Supplementary Table S1), with occupancies of 0.13 and 0.83 for G3 and G4, respectively. They are both covalently bound to Glu245 (Fig. 6d). Monomer $C$ has G2, G3 and G4 molecules

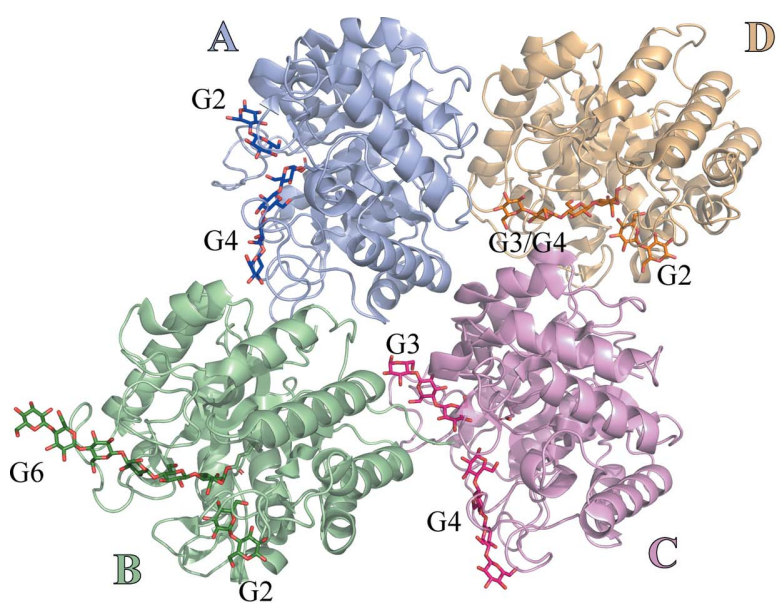

(a)

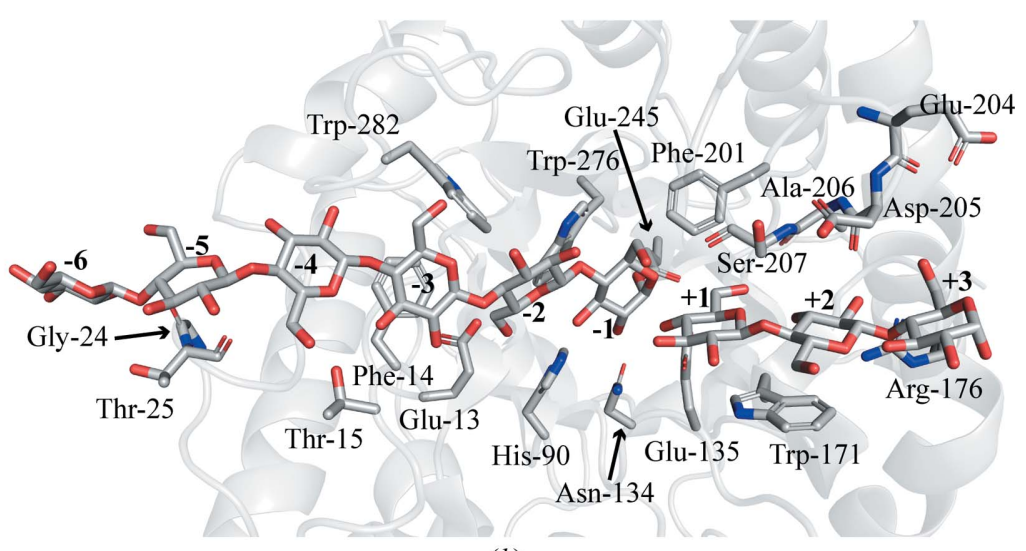

(b)

Figure 5

(a) Overall structure of RBcel1_Y201F co-crystallized with cellotriose (PDB entry 7p6j). The monomers in the asymmetric unit are highlighted as follows: monomer $A$ in blue, monomer $B$ in green, monomer $C$ in pink and monomer $D$ in orange. Their respective ligands are shown in darker colors. $(b)$ Representation of the whole catalytic cleft of RBcell consisting of the -6 to -1 subsites and the +1 to +3 subsites. The residues interacting with the ligand are emphasized. 
placed in the -5 to -2 subsites (i.e. not covalently bound to Glu245). Intriguingly, electron density was also observed at the -1 subsite which cannot be explained by a sugar ring (Fig. 6c). Several water molecules were placed in the model, but they are not sufficient to account for this excess of density. Unexpectedly, a G6 molecule is covalently bound to Glu245 in monomer $B$ (Fig. $6 b$ ). Only four negatively numbered subsites have been described so far (Delsaute et al., 2013; Collet et al., 2021). However, the presence of G6 in the negatively numbered subsites of RBcel1 in monomer $B$ allowed the definition of two additional subsites: -5 and -6 . Inside these, the sugar moieties interact with the carbonyl of Gly24 and Thr25 (Fig. 6b). Additional interactions are provided from monomer $C$ of a neighboring asymmetric unit (Fig. 7). Indeed, the $\mathrm{N}$-terminal amine of Ser1 interacts with $\mathrm{O} 3$ and $\mathrm{O} 1$ of the sugar moieties in the -5 and -6 subsites, respectively. In addition, the carbonyl of Ser313 and the carboxylate of Asp314 closely interact with O3 and O4 at the nonreducing end of G6. Such interactions between monomer $C$ and the covalently bound G6, however, could be fortuitous, resulting from a symmetry contact artifact.

As discussed in our previous study, a displacement of the Glu245 side chain to form the GEI, adopting the $\mathbf{t t} 0^{\circ}$ conformation instead of mt- $10^{\circ}$, results in a change of electronic environment (Collet et al., 2021). In the structure of RBcel1_Y201F in complex with G3, the same displacement of the side chain of Glu245 was observed in monomers $A, B$ and $D$, where a ligand is covalently bound (Fig. $8 a$ ). The Glu245 side chain, however, remains in the $\mathbf{m t}-10^{\circ}$ conformation in monomer $C$, where G4 does not occupy the -1 subsite (Fig. 8a). Since both conformations of the nucleophile residue occur in the same structure, the displacement must be related to the formation of the GEI and is not an artifact resulting from the Tyr201Phe substitution.

Regarding the positively numbered subsites, monomers $A$, $B$ and $D$ have a G2 molecule located in the +1 and +2 subsites (Fig. 5 and Supplementary Fig. S3). In monomer $C$, however, a G3 molecule occupies the +1 to +3 subsites, as in the structure of RBcel1_E135Q. According to the PACE analysis, RBcel1 uses both G2 and G3 as acceptors, although the latter is a better acceptor than the former. A superposition of the four monomers of the RBcel1_Y201F structure should allow a visualization of whether G2 and G3 adopt different positions (Fig. 8a). The position of the G2 molecule was found to be nearly identical in monomers $A, B$ and $D$. On the contrary, the occupancy of the third positive subsite clearly brings the

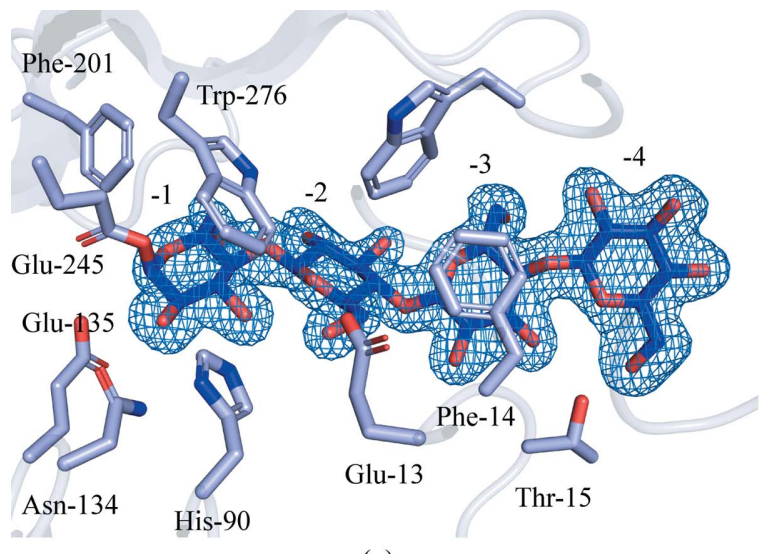

(a)

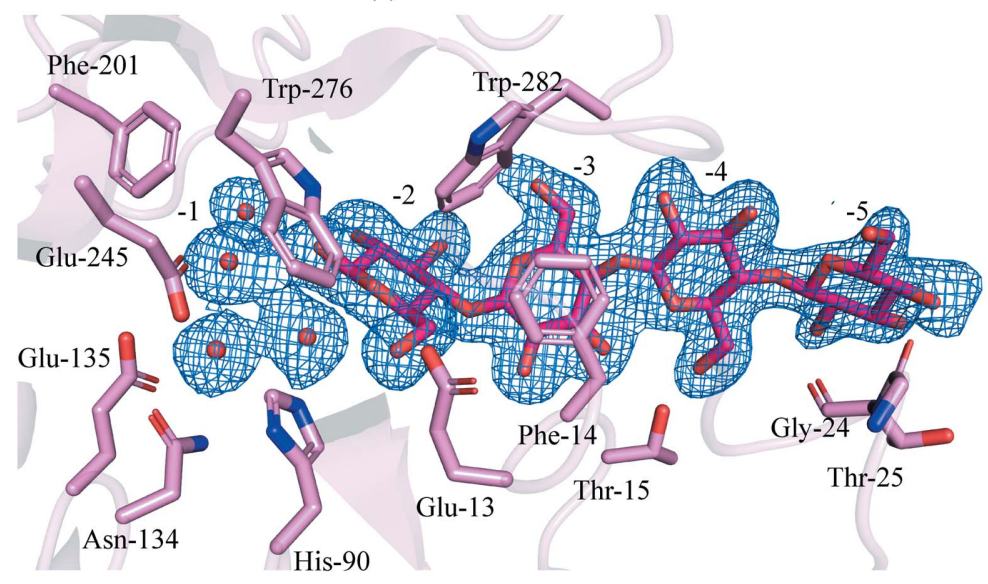

(c)

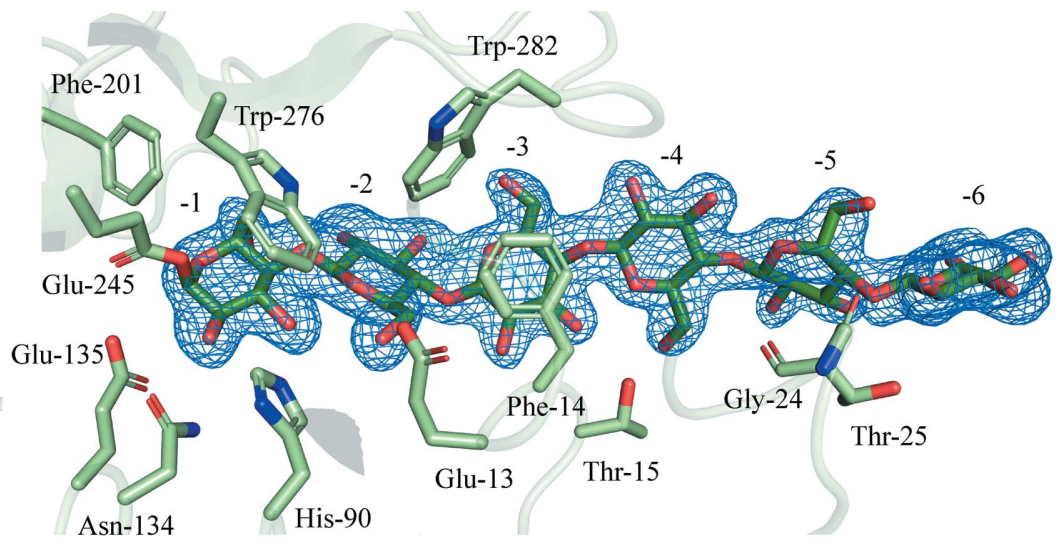

(b)

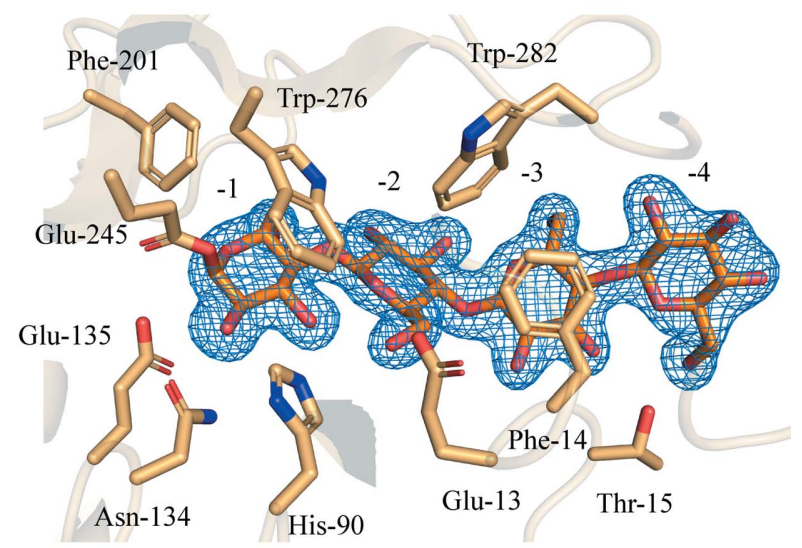

(d)

Figure 6

Close-up view of the donor-binding sites in the structure of RBcel1_Y201F co-crystallized with G3. (a) Monomer $A$ with G4 in its -1 to -4 subsites. (b) Monomer $B$ with G6 in its -1 to -6 subsites. (c) Monomer $C$ with G4 in its -2 to -5 subsites and four water molecules in its -1 subsite. $(d)$ Monomer $D$ with G3 and G4 in its -1 to -4 subsites. The residues composing each subsite are emphasized. The $2 F_{\mathrm{o}}-F_{\mathrm{c}}$ map around each cellooligosaccharide is shown as a blue mesh. 
glucose unit in the +1 subsite closer to $\mathrm{Glu}_{\mathrm{A} / \mathrm{B}}$. Indeed, $\mathrm{G} 3$ in monomer $C$ is translated by $0.74 \AA$ compared with $\mathrm{G} 2$, as shown in Fig. 8(b). As a result, the nonreducing end lies $2.66 \AA$ from OE1 of Glu135 and, potentially, $2.64 \AA$ from the reducing end of a bound donor. By comparison, these distances are increased to 2.81 and $3.43 \AA$, respectively, when G2 occupies the +1 and +2 subsites.

\section{Conclusion}

In this work, we have combined structural biology with enzymatic assays in order to better understand the molecular factors that govern transglycosylation in RBcel1. Substituting the conserved Tyr201 residue allowed us to resolve the first structure of a GH5 enzyme in complex with transglycosylation products with the two catalytic glutamate residues unmodified. By co-crystallizing RBcel1_Y201F with G3, the GEI was trapped with G3, G4 and G6 covalently bound to Glu245. Thanks to the presence of G6, the -5 and -6 subsites were identified, which could not be observed or predicted from previously released structures of RBcel1 (Delsaute et al., 2013; Collet et al., 2021). We have also shown that transglycosylation is dependent on the size of the donor and acceptor sugars. Transglycosylation products accumulate with an acceptor of at least three glucose units. Thus, for transglycosylation to proceed efficiently, a third positive subsite identified in the structure of Rbcel1_E135Q in complex with cellotriose must be occupied by a glucose unit. On the contrary, hydrolysis requires only the first two positive subsite to be occupied since cellobiose is the most abundant hydrolysis product. Several studies have shown the importance of the acceptor for various GHs (Pollock \& Sharon, 1970; Armand et al., 2001; Faijes et al., 2003; Zakariassen et al., 2011; Madhuprakash et al., 2012; Wang et al., 2014; Qin et al., 2017; Garcia-Oliva et al., 2019; Zhao et al., 2021). To our knowledge, this structural study is the first to show how the acceptor length influences transglycosylation. The occupation of the +1 to +3 subsites brings the

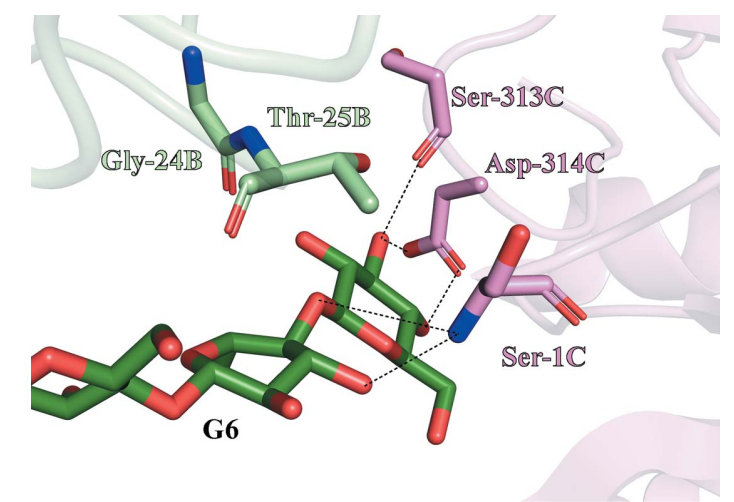

Figure 7

Close-up view of the -5 and -6 subsites of monomer $B$ in the structure of RBcel1_Y201F in complex with G3. Monomer $B$ and its bound G6 are shown in green. Gly 24 and Thr 25 composing the -5 and -6 subsites are emphasized. Additional interactions with G6 are provided from monomer $C$ of a neighboring asymmetric unit (shown in pink). Ser1, Ser313 and Asp314 of monomer $C$ are emphasized as well as their interactions with G6 (dashed lines). acceptor closer to $\mathrm{Glu}_{\mathrm{A} / \mathrm{B}}$ and the covalently linked donor, which could explain why transglycosylation is better with G3 as an acceptor than G2. Taken together with the data from our previous study on RBcel1, this work shows that occupation of the $-3,-2$ and +3 subsites induces definite movements of the key residues at the catalytic site (Glu135, Tyr201 and Glu245).

Finally, we have shown that the $\mathrm{pH}$ regulates the ratio of hydrolysis to transglycosylation. Indeed, transglycosylation products are more abundant at basic $\mathrm{pH}$, where hydrolysis is reduced. With good leaving groups such as CIPNP, the GEI is formed without the protonic assistance of Glu135, which could remain deprotonated and poised for transglycosylation at basic $\mathrm{pH}$. Whether this modulation of hydrolysis versus transglycosylation by $\mathrm{pH}$ is of biological significance remains to be investigated. RBcel1 was identified during a metagenomic survey of an Antarctic soil sample collected from an oil-contaminated site (Berlemont et al., 2009). Currently, its closest homolog is a GH5 enzyme from $P$. saliphila (locus WP_15030527), with 97\% identity. Such homology suggests that RBcel1 originates from a Pseudomonas species that may

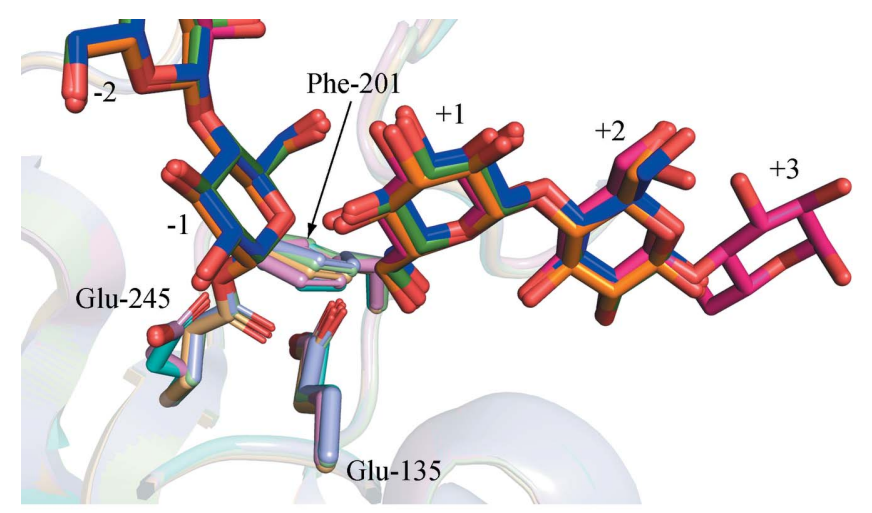

(a)

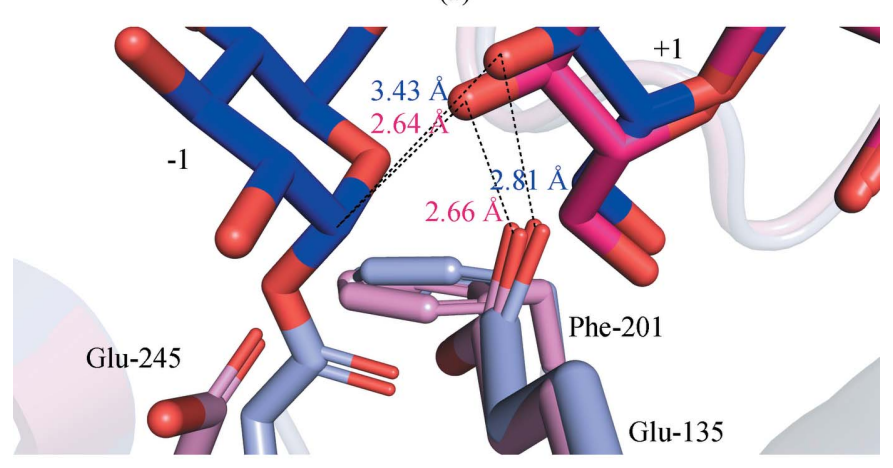

Figure 8

(b)

(a) Structural alignment of the four monomers of RBcel1_Y201F showing the position of the side chain of Glu245 and the ligands in the +1 to +3 subsites. Monomers $A, B, C$ and $D$ are represented in blue, green, pink and orange, respectively. To highlight the displacement of the side chain of Glu245 on the formation of the GEI, the apo-form structure of RBcel1_Y201F was added to the alignment (cyan; PDB entry 7p6i). G2 is found in the +1 to +2 subsites in monomers $A, B$ and $D$, while $\mathrm{G} 3$ lies in the +1 to +3 subsites in monomer $C$. (b) Close-up view of the -1 and +1 subsites showing the structural changes when G3 is bound in the positively numbered subsites instead of G2. For the sake of clarity, only the superposition of monomer $A$ (blue) with monomer $C$ (pink) is shown. The distances between $\mathrm{O} 4$ of the acceptor sugar and $\mathrm{C} 1$ of the GEI or OE1 of Glu135 are given in the respective colors of monomers $A$ and $C$. 
be related to $P$. saliphila and $P$. profundi. Interestingly, both species show optimal growth at a basic $\mathrm{pH}$ of around 8.0-9.0 (Sun et al., 2018; Zhang et al., 2020), which would favor the transglycosylation activity of RBcel1.

The physiological role of bacterial transglycosylases remains to be elucidated. Berlemont et al. (2009) postulated that RBcel1 could be involved in cellulose synthesis. Indeed, RBcel1 has $48 \%$ identity to Ps_Cel5A from P. stutzeri strain A1501, a bacterium that forms a biofilm made of cellulose (Ude et al., 2006). In some bacterial species such as E. coli, a gene encoding a GH8 endoglucanase, BcsZ, is commonly found in the $b c s$ operon responsible for cellulose synthesis (Römling \& Galperin, 2015). In Rhizobium leguminosarum and Komatagaeibacter xylinus, BcsZ has been shown to control the size and shape of cellulose fibrils (Robledo et al., 2012; Nakai et al., 2013). In the genome of $P$. stutzeri, however, there is no gene encoding a GH8 endoglucanase. Thus, Ps_Cel5A could achieve the same function as that of BcsZ (Berlemont et al., 2009). However, one may wonder how transglycosylation could be relevant to the synthesis of bacterial cellulose. Several GHs acting as transglycosylases have been shown to be directly involved in the synthesis of plant cell-wall polysaccharides (Schröder et al., 2004; Eklöf \& Brumer, 2010; Nishikubo et al., 2011; Franková \& Fry, 2013). Their ability to 'cut and paste' allows the rearrangement of cell-wall polysaccharides during plant growth, cell-wall repair and cell differentiation (Franková \& Fry, 2013). Such a rearrangement activity is also found in transglycosylases from phytopathogenic fungi, as shown in Botrytis cinerea (Bi et al., 2021). Since $P$. stutzeri is a plant commensal (Pham et al., 2017; Sun et al., 2021), an additional role of transglycosylating GHs could be in the host-interaction mechanism.

\section{Acknowledgements}

We thank Marc Demarez for his technical assistance in purifying RBcel1 and René Witjens for his critical review of the structural part of this article.

\section{Funding information}

The following funding is acknowledged: Fonds De La Recherche Scientifique - FNRS (contract No. IISN 4.4503.11F) and the MX Block Allocation Group at SOLEIL (contract Nos. 20151139, 20171555 and 20191372).

\section{References}

Abdul Manas, N. H. M., Illias, R. \& Mahadi, N. M. (2018). Crit. Rev. Biotechnol. 38, 272-293.

Armand, S., Andrews, S. R., Charnock, S. J. \& Gilbert, H. J. (2001). Biochemistry, 40, 7404-7409.

Benkoulouche, M., Fauré, R., Remaud-Siméon, M., Moulis, C. \& André, I. (2019). Interface Focus, 9, 20180069.

Berlemont, R., Delsaute, M., Pipers, D., D'Amico, S., Feller, G., Galleni, M. \& Power, P. (2009). ISME J. 3, 1070-1081.

Bi, K., Scalschi, L., Jaiswal, N., Mengiste, T., Fried, R., Sanz, A. B., Arroyo, J., Zhu, W., Masrati, G. \& Sharon, A. (2021). Nat. Commun. 12, 2166.

Bissaro, B., Monsan, P., Fauré, R. \& O'Donohue, M. J. (2015). Biochem. J. 467, 17-35.
Boltje, T. J., Buskas, T. \& Boons, G.-J. (2009). Nat. Chem. 1, 611-622. Chen, V. B., Arendall, W. B., Headd, J. J., Keedy, D. A., Immormino, R. M., Kapral, G. J., Murray, L. W., Richardson, J. S. \& Richardson, D. C. (2010). Acta Cryst. D66, 12-21.

Collet, L., Vander Wauven, C., Oudjama, Y., Galleni, M. \& Dutoit, R. (2021). Acta Cryst. D77, 205-216.

Crout, D. H. \& Vic, G. (1998). Curr. Opin. Chem. Biol. 2, 98-111.

Danby, P. M. \& Withers, S. G. (2016). ACS Chem. Biol. 11, 1784-1794.

Davies, G. J., Wilson, K. S. \& Henrissat, B. (1997). Biochem. J. 321, 557-559.

Delsaute, M., Berlemont, R., Dehareng, D., Van Elder, D., Galleni, M. \& Bauvois, C. (2013). Acta Cryst. F69, 828-833.

Desmet, T., Cantaert, T., Gualfetti, P., Nerinckx, W., Gross, L., Mitchinson, C. \& Piens, K. (2007). FEBS J. 274, 356-363.

Dilokpimol, A., Nakai, H., Gotfredsen, C. H., Baumann, M. J., Nakai, N., Abou Hachem, M. \& Svensson, B. (2011). Biochim. Biophys. Acta, 1814, 1720-1729.

Ducros, V., Czjzek, M., Belaich, A., Gaudin, C., Fierobe, H.-P., Belaich, J.-P., Davies, G. J. \& Haser, R. (1995). Structure, 3, 939-949.

Dutoit, R., Delsaute, M., Collet, L., Vander Wauven, C., Van Elder, D., Berlemont, R., Richel, A., Galleni, M. \& Bauvois, C. (2019). Acta Cryst. D75, 605-615.

Eklöf, J. M. \& Brumer, H. (2010). Plant Physiol. 153, 456-466.

Emsley, P., Lohkamp, B., Scott, W. G. \& Cowtan, K. (2010). Acta Cryst. D66, 486-501.

Faijes, M., Pérez, X., Pérez, O. \& Planas, A. (2003). Biochemistry, 42, 13304-13318.

Ferrer, J.-L. (2001). Acta Cryst. D57, 1752-1753.

Franková, L. \& Fry, S. C. (2013). J. Exp. Bot. 64, 3519-3550.

Garcia-Oliva, C., Hoyos, P., Petrásková, L., Kulik, N., Pelantová, H., Cabanillas, A. H., Rumbero, Á., Křen, V., Hernáiz, M. J. \& Bojarová, P. (2019). Int. J. Mol. Sci. 20, 6181.

Garsoux, G., Lamotte, J., Gerday, C. \& Feller, G. (2004). Biochem. J. 384, 247-253.

Geyer, H. \& Geyer, R. (2006). Biochim. Biophys. Acta, 1764, 18531869.

Golovin, A. \& Henrick, K. (2008). BMC Bioinformatics, 9, 312.

Gonçalves, A. M. D., Silva, C. S., Madeira, T. I., Coelho, R., de Sanctis, D., San Romão, M. V. \& Bento, I. (2012). Acta Cryst. D68, 14681478.

Kabsch, W. (2010). Acta Cryst. D66, 125-132.

Karplus, P. A. \& Diederichs, K. (2015). Curr. Opin. Struct. Biol. 34, 60-68.

Kiessling, L. L. \& Splain, R. A. (2010). Annu. Rev. Biochem. 79, 619653.

Kim, H.-W. \& Ishikawa, K. (2011). Biochem. J. 437, 223-230.

Li, C. \& Wang, L.-X. (2016). Adv. Carbohydr. Chem. Biochem. 73, 73-116.

Liebschner, D., Afonine, P. V., Baker, M. L., Bunkóczi, G., Chen, V. B., Croll, T. I., Hintze, B., Hung, L.-W., Jain, S., McCoy, A. J., Moriarty, N. W., Oeffner, R. D., Poon, B. K., Prisant, M. G., Read, R. J., Richardson, J. S., Richardson, D. C., Sammito, M. D., Sobolev, O. V., Stockwell, D. H., Terwilliger, T. C., Urzhumtsev, A. G., Videau, L. L., Williams, C. J. \& Adams, P. D. (2019). Acta Cryst. D75, 861-877.

Lundemo, P., Karlsson, E. N. \& Adlercreutz, P. (2017). Appl. Microbiol. Biotechnol. 101, 1121-1131.

Madhuprakash, J., Tanneeru, K., Purushotham, P., Guruprasad, L. \& Podile, A. R. (2012). J. Biol. Chem. 287, 44619-44627.

McCoy, A. J., Grosse-Kunstleve, R. W., Adams, P. D., Winn, M. D., Storoni, L. C. \& Read, R. J. (2007). J. Appl. Cryst. 40, 658-674.

Monsan, P., Remaud-Siméon, M. \& André, I. (2010). Curr. Opin. Microbiol. 13, 293-300.

Nakai, T., Sugano, Y., Shoda, M., Sakakibara, H., Oiwa, K., Tuzi, S., Imai, T., Sugiyama, J., Takeuchi, M., Yamauchi, D. \& Mineyuki, Y. (2013). J. Bacteriol. 195, 958-964. 
Nishikubo, N., Takahashi, J., Roos, A. A., Derba-Maceluch, M., Piens, K., Brumer, H., Teeri, T. T., Stålbrand, H. \& Mellerowicz, E. J. (2011). Plant Physiol. 155, 399-413.

Oikawa, T., Tsukagawa, Y., Chino, M. \& Soda, K. (2001). Biosci. Biotechnol. Biochem. 65, 1889-1892.

Patrick, W. M., Nakatani, Y., Cutfield, S. M., Sharpe, M. L., Ramsay, R. J. \& Cutfield, J. F. (2010). FEBS J. 277, 4549-4561.

Pham, V. T. K., Rediers, H., Ghequire, M. G. K., Nguyen, H. H., De Mot, R., Vanderleyden, J. \& Spaepen, S. (2017). Arch. Microbiol. 199, 513-517.

Pollock, J. \& Sharon, N. (1970). Biochemistry, 9, 3913-3925.

Qin, Z., Yang, S., Zhao, L., You, X., Yan, Q. \& Jiang, Z. (2017). J. Biol. Chem. 292, 1666-1678.

Robledo, M., Rivera, L., Jiménez-Zurdo, J. I., Rivas, R., Dazzo, F., Velázquez, E., Martínez-Molina, E., Hirsch, A. M. \& Mateos, P. F. (2012). Microb. Cell Fact. 11, 125.

Römling, U. \& Galperin, M. Y. (2015). Trends Microbiol. 23, 545557.

Rosengren, A., Hägglund, P., Anderson, L., Pavon-Orozco, P., Peterson-Wulff, R., Nerinckx, W. \& Stålbrand, H. (2012). Biocatal. Biotransformation, 30, 338-352.

Sakon, J., Adney, W. S., Himmel, M. E., Thomas, S. R. \& Karplus, P. A. (1996). Biochemistry, 35, 10648-10660.
Schröder, R., Wegrzyn, T. F., Bolitho, K. M. \& Redgwell, R. J. (2004). Planta, 219, 590-600.

Sun, J., Wang, W., Ying, Y., Zhu, X., Liu, J. \& Hao, J. (2018). Int. J. Syst. Evol. Microbiol. 68, 1776-1780.

Sun, X., Xu, Z., Xie, J., Hesselberg-Thomsen, V., Tan, T., Zheng, D., Strube, M. L., Dragoš, A., Shen, Q., Zhang, R. \& Kovács, Á. T. (2021). ISME J., https://doi.org/10.1038/s41396-021-01125-3.

Ude, S., Arnold, D. L., Moon, C. D., Timms-Wilson, T. \& Spiers, A. J. (2006). Environ. Microbiol. 8, 1997-2011.

Varki, A. (2017). Glycobiology, 27, 3-49.

Wang, H., Ma, R., Shi, P., Xue, X., Luo, H., Huang, H., Bai, Y., Yang, P. \& Yao, B. (2014). Appl. Biochem. Biotechnol. 174, 328-338.

Wong, C. \& Krasnova, L. (2019). Isr. J. Chem. 59, 18-22.

Zakariassen, H., Hansen, M. C., Jøranli, M., Eijsink, V. G. H. \& Sørlie, M. (2011). Biochemistry, 50, 5693-5703.

Zhang, X.-J., Liu, H.-C., Zhou, Y.-G., Wu, X.-L., Nie, Y., Li, Q.-R., Wang, M.-Z., Zhao, L., Cai, M. \& Kang, Y.-Q. (2020). Curr. Microbiol. 77, 1924-1931.

Zhao, J., Tandrup, T., Bissaro, B., Barbe, S., Poulsen, J. N., André, I., Dumon, C., Lo Leggio, L., O’Donohue, M. J. \& Fauré, R. (2021). New Biotechnol. 62, 68-78.

Zheng, B., Yang, W., Zhao, X., Wang, Y., Lou, Z., Rao, Z. \& Feng, Y. (2012). J. Biol. Chem. 287, 8336-8346. 